\title{
Strategically Measuring Quality of Existing Building Stock
}

\author{
Arie Stapper ${ }^{1} \&$ Christoph Maria Ravesloot ${ }^{1,2}$ \\ ${ }^{1}$ Business School Netherlands, Buren, The Netherlands \\ ${ }^{2}$ Rotterdam University of Applied Sciences, Rotterdam, The Netherlands. E-mail: c.m.ravesloot@hr.nl \\ Correspondence: Arie Stapper, Stapper Advies BV, Dorpsstraat 32, 2902BD Capelle aan den IJssel, Netherlands. \\ E-mail: mail@stapper.eu
}

Received: December 10, 2019

Accepted: April 24, 2020

Online Published: April 28, 2020

doi:10.5539/mas.v14n5p63

URL: https://doi.org/10.5539/mas.v14n5p63

\begin{abstract}
Dutch housing corporations generally have two methods of assessing the strategic value of existing housing stock. The first is by calculating the financial return on investments with a life expectancy of fifty to sixty years. The second method is to balance the technical quality against maintenance and renovation planning. A Dutch housing corporation needed a integrated method, so in a single case study, a new method was developed based on research on how to monitor the technical and financial assets better.

Four problems were detected: (1) the existing strategy did not seem to be resilient to future changes, (2) there was no instrument for measuring progress, (3) there was no way to translate strategic data to individual estates and (4) there was no instrument for monitoring the results of improvements set off against the strategic goals.

With one integrated tool to fix these four problems, an integrated approach to a closed asset management strategy and policy would be available. Such a tool would make it possible to make adjustments to the strategy based on facts gained by measuring the results of former adjustments to the strategy. The goal of this paper is to present the research supporting the design of a new model.

The result, the so called Return Matrix, is a fully elaborated model. It supports the management team in decision making about strategy (five years) and vision (twenty years) development. It creates insight into and support for the outcome of the strategy among policy professionals, staff and colleagues. And finally, it creates understanding among the tenants, it $\mathrm{s}$ understood and supported by the civil servants and gets approval and agreement of cooperation from the municipal executives.

With the knowledge gained by this study, it will not be difficult to compose the instrument for other cases too.

Keywords: asset management, dutch social housing corporation, Netherlands, return matrix, financial return, social return, strategy measurement model, woningcorporatie

\section{Introduction}

Dutch housing corporations generally have two methods of assessing the strategic value of existing housing stock. The first is by calculating the financial return on investments with a life expectancy of fifty to sixty years. The second method is to balance the technical quality against maintenance and renovation planning, mostly based on past experience and personal estimation by maintenance officials. However, a combination of both methods is needed for strategically planning sustainable renovation of existing building stock. After all, the budget can only be spent once.
\end{abstract}

\subsection{Introduction of the Problem}

A Dutch housing corporation in Velsen recognised this strategic problem because of expected, rapidly emerging, technical and financial changes as well as changing governmental and municipality policies. Therefore, housing corporations in general, and this housing corporation in particular, needed a more accurate method of monitoring technical and financial performance indicators for the renovation of existing building stock within strategic asset management for social housing. In an exploring single case study for the housing corporation Velsen, research was carried out to gain the knowledge necessary to develop and test a new method to better monitor the technical and financial assets. This method also had to reflect on possibilities to communicate the results more directly amongst professionals from the housing corporation and to private and public partners. 


\subsection{The Importance of the Problem}

Four strategic problems were detected in the daily routine of asset management: (a) the existing strategy did not seem to be resilient to future changes, (b) there was no instrument for measuring progress, (c) strategic data could not be translated to individual estates; and, finally, (d) there was no instrument for monitoring the results of improvements set off against the strategic goals.

Dutch housing corporations in general, and Velsen housing corporation in particular, could solve these four strategic problems, if they had one integrated tool. An integrated approach to a closed asset management strategy and policy would allow them to make adjustments to the strategy based on facts gained by measuring the results of former adjustments to the strategy. A majority of the Dutch social housing stock is old and out of date. The quality is poor, which means tenants pay little rent. This is true for Velsen too.

Policy makers have little idea of what is the best strategy of improvement. Even if they had, there would be no instrument to test an improved strategy. Besides, changes in Dutch public policies and changing financial conditions have to be anticipated.

\subsection{The Question Central to the Purpose}

As said before, housing corporations generally have two methods of assessing the strategic value of existing housing stock: the financial return on investments and the technical quality. Both methods were insufficient to determine what strategy would be best. Therefore, this housing corporation needed a more accurate method of monitoring technical and financial performance indicators for existing building stock within strategic portfolio management for social housing. So it was a problem the Housing Company can not measure the strategy.

\section{Method}

The main question of the research focusses on the single case study of the Velsen housing corporation: In what way can housing corporation Velsen develop a tool for strategic asset management policy with good technical and financial detail?

The aim of the research is to gain knowledge about key performance indicators and other ingredients necessary for a strategic asset management tool. This knowledge will be used to develop a visual monitoring instrument that will make proper discussion and decision making, based on shared facts about the real technical and financial performance of existing building stock, possible. A serious strategic challenge like this asks for a very reliable result. For this reason, an applied scientific approach has been adopted. An extra step in the verification of the process and in the validation of the results has been added to increase accountability and reliability.

\subsection{Literature Research}

Firstly, literature research was executed to get more knowledge about the known fail and success factors of strategic asset management for housing corporations and in social housing. What would be the conditions for making a strategic asset management policy work properly and for making it resilient? Also, performance indicators in strategic asset management and in housing policies were looked for, both with private parties and with public authorities.

Table 1. keywords and sources

\begin{tabular}{cc}
\hline Concern & Keywords, sources \\
\hline Single search & $\begin{array}{c}\text { BIM, Big Data, added value, collaboration, support, result, vision, } \\
\text { mission, strategy, social housing, NOM, renewable, circular, } \\
\text { renew, renovate, rejuvenate, aging, sustainability, energy, } \\
\text { social housing estate planning } \\
\text { Composed search } \\
\text { social housing Dutch quality measurement } \\
\text { critical evaluation Dutch social housing } \\
\text { scholar.google.nl } \\
\text { Library of ASRE }\end{array}$ \\
\hline
\end{tabular}

The literature research ought to show the fail and success factors of strategic asset management for housing corporations and in social housing. What would be conditions to make a strategic asset management policy work properly and make it resilient? Also was looked for performance indicators in strategic asset management and in housing policies, both from private parties as from public authorities. In order to increase reliability, experts were interviewed on the subject matter. 


\subsection{Interviews}

Secondly, involved professionals from the housing corporation and stakeholders were interviewed about strategic policy making in the case of Velsen. What strategic policy is used at the housing corporation and what kinds of strategic policy are known in literature and amongst professionals? An overview of policies and their opportunities and risks was made. Special attention was given to the question of how to discuss and how to decide on the norms for a future resilient strategic asset management policy. The external interviews with the most important stakeholders should give criteria for a detailed financial and technical evaluation of existing building stock. To get this information and leave room for unexpected information, semi structured interviews with partly fixed and partly open questions were designed. The DESTEP analysis method was adopted for the SWOT diagram. In the case study of Velsen, this matches the quality and results of the previous asset management tool.

\subsection{Compare the Options}

Thirdly, literature provided some models of which the information could be compared and combined into some alternate options. A morphological mapping method with the above mentioned and prioritised criteria was used to compare the options, leading to the model which was best fit for its purpose and combining technical and financial perspectives in a strategic asset management tool.

\subsection{Tthe Factors and the KPI's}

Fourthly, comparing the factors found in literature as well as in the interviews and the analyses, gave insight into the possibly useful ingredients of a tool. Comparing the factors and assessing them to decide which were useful in general and in the specific situation of the case Velsen, a selection was made. For each factor, as many KPIs as possible were selected, with criteria for each KPI. This was done to increase reliability. For the Velsen case, a proposal for decision making was made, based on proportional distribution. The final KPIs and their weight were chosen and by the management team of Velsen.

To improve communication with the users, the result was simplified by presenting it as a linearly scaled scored number between zero and ten. For each KPI, the score number of six is determined to mean 'sufficient', as in “just good enough' and the score number of ten is set to be 'the highest score possibly wished for'. This means a score higher than ten will be ten, and lower than zero will be zero.

\subsection{Implementation}

The fifth step was the first implementation of the model at Velsen. All data were collected on the level of the 6.500 separate housing units. To minimize the effect of outliers, each KPI was calculated on the lowest level (6.500 separate units) before determining the average. To establish that the instrument and the outcomes would be robust, a data expert was asked to check the data, the data processing and the outcomes.

\subsection{Reliability Check}

As a final step, the reliability of the model was checked. At the Velsen organization, little identified and classified information was available. To increase the reliability of the model, new information was gathered for validation of the outcome of the model and validation of the model itself. The organization consists of separate teams dealing with four elements (technics, rentability, livability and finance). Each team has its own specific knowledge of the housing stock. So, for validation, these four knowledge groups were defined in four factors. Because the knowledge was unclassified and unidentified in this case, the traffic light method was used to identify the information and to classify the information for each factor. A meeting was organised for each factor and people with relevant knowledge and experiential experts were invited. In preparation of the group meetings, maps of the neighborhoods of the city of Velsen were made. In these maps, the four elements of housing stock of the corporation was visualized by color. During the meeting, the experiential experts were asked to give each stock of houses a green $(=$ good), yellow (= moderate) or red (= bad) sticker. Subsequently, they were asked for their top ten of red and their top ten of green. In this way, a five-point-scale for each factor was found, revealing knowledge from experts and sharing it. To validate these data and to increase reliability, a discussion was organised at the end of the meeting. After this discussion, minor changes were allowed for. 


\section{Results}

Literature research was carried out to find out about the known fail and success factors of strategic asset management for social housing corporations. What would be conditions for making a strategic asset management policy work properly and for making it resilient? Additional literature research was done on the performance indicators (KPIs) in strategic asset management, in housing policies, with private parties and public authorities.

\subsection{Recent Scientific Literature}

The search for scientific literature has yielded a broad spectrum of articles, such as those on the effect of the development of social real estate to be seen as an investment on our government (Loon, 2017), on the effect on housing associations, not regarding the value of real estate, but regarding the development of the values of the organization (Nieboer \& Gruis, 2016), on making homes sustainable for the elderly and how to involve them (Boerenfijn, 2018), on the effect of financial crisis on new construction and land policy and on renovations and real estate strategy (Buitelaar, 2016), on the relationship between government policy and rent policy (Tu, 2015), on the financial problems of Vestia and an explanation of the "economization" of the social housing sector (Aalbers, 2017), and on the development of an evaluation model to support the decisions of public authorities, which influence urban renewal and social housing, and which were implemented with the involvement of private investors (Tajani, 2015).

\subsection{Older Scientific Literature}

This search for information led to an additional amount of (indirectly) useful literature. Firstly, a publication about the potential applications of performance measurement as well as the indicators that can be used to measure financial and social returns. "The Net Present Value is the Most Relevant Indicator" (Gruis, 2005). Also, 26 social return indicators in 4 categories are described in this article.

Secondly, a report by the Sheffield housing department, which stated: "Social theory is all very well, but the opinions of the people who live there should be the criterion by which the success or failure of Park Hill must be measured" (Hollow, 2010). Nieboer (2005) stated that real estate investors in the Netherlands decide about physical and technical development only partly by using their reasoning: the decisions are also partly based on intuition. The periodic evaluations for strategic stock management would only be based on financial calculations to weigh competing signals and interests. Some stated that a systematic weighing of other relevant aspects is unnecessary or even unrealistic. Despite the periodic evaluations of all estates, landlords would not have a systematic approach to weigh the relative importance of the different aspects. Consequently, this part of the process remains a 'black box'.

According to Mossel (2010), the maintenance of heating and water systems and maintenance of hinges and locks of windows and external doors are the very important maintenance services of housing associations to customers. The exterior paintwork has a high importance when obtained with the regression analysis method, but not when directly asked. Veenhoven (2002) states that social policy makers need both objective and subjective indicators. Though subjective indicators have their limitations, objective indicators also labor under serious shortcomings. For some purposes objective indicators are best suited, for other uses subjective indicators are preferable. The challenge of social reporting is to combine the strengths of these indicators and to make sense of the discrepancies they show.

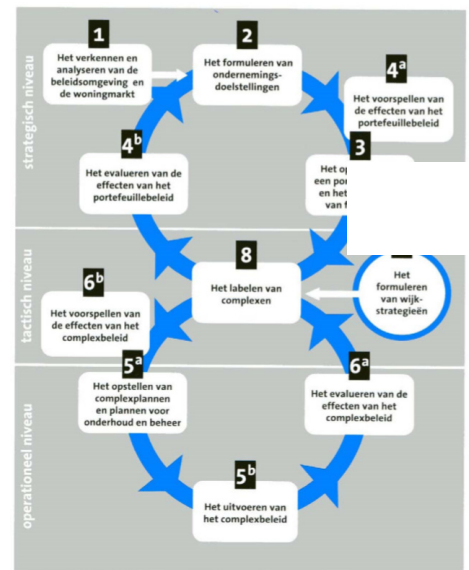

Figure 1. Beleids8baan (Conijn, 2013) 


\section{Relevance}

Although these are all fascinating and some (indirectly) helpful articles, I have not come across any actual scientific literature that can directly help to come up with a good instrument to test a portfolio plan of Woningbedrijf Velsen.

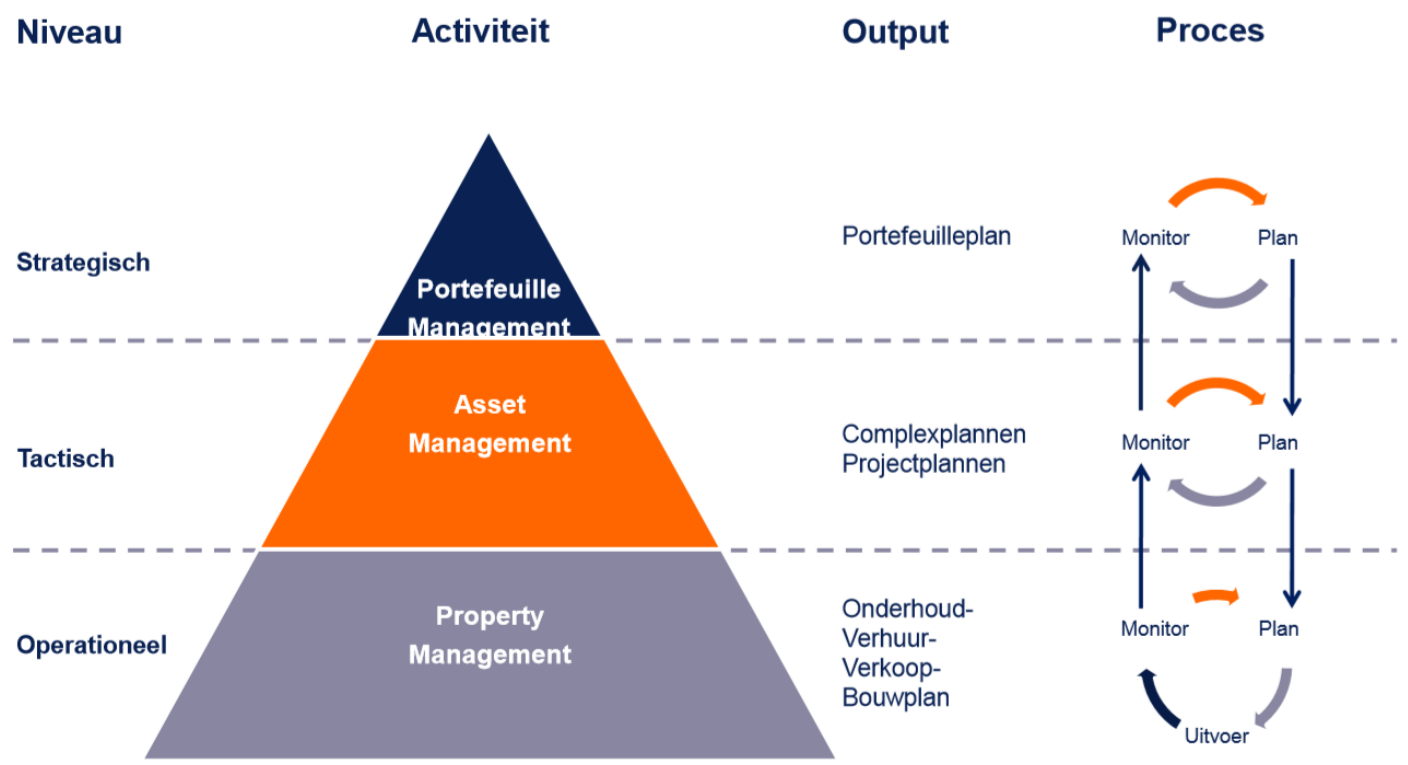

Figure 2. Real Estate pyramid (Conijn, 2013)

\subsection{Professional Literature}

Some professional literature about models for the Dutch social housing corporations exists only in Dutch language. It describes the process of making a real estate strategy. The model connects the strategic process with de tactical and operational process. This model is called the 'Beleids8baan' (figure 1) and is widely used by Dutch housing corporations (Os, 2013).

Ortec Finance has integrated the activities, output and process on the levels Strategy, Tactics and Operations in one picture (figure 2: The Real Estate Pyramid). The output of the Real Estate Strategy is defined as the 'Portefeuilleplan' and this covers five years in the future of the housing corporation (Conijn, 2013).

The BCG matrix is an instrument for strategic decision making. Two of the largest Dutch housing corporations use a similar model (Conijn, 2017). These corporations are Havensteder and Vestia. This model is called the 'Rendementsmatrix'. This model looks useful, although there is no description of the model or how it has been composed.

\subsection{Interviews with Experts}

A model like the BCG matrix can also be found in literature. In Dutch it is called the 'Rendementsmatrix' (Conijn, 2013), the English translation would be 'Return Matrix'. This model is described by Ortec-finance as an instrument for strategic decision making for Dutch social housing corporations. This model looks like the BCG matrix. Both have two axes and four squares. The BCG matrix uses the axes 'marked share' and 'growth rate'. The Return Matrix uses the axes 'financial return' and 'social return'. 


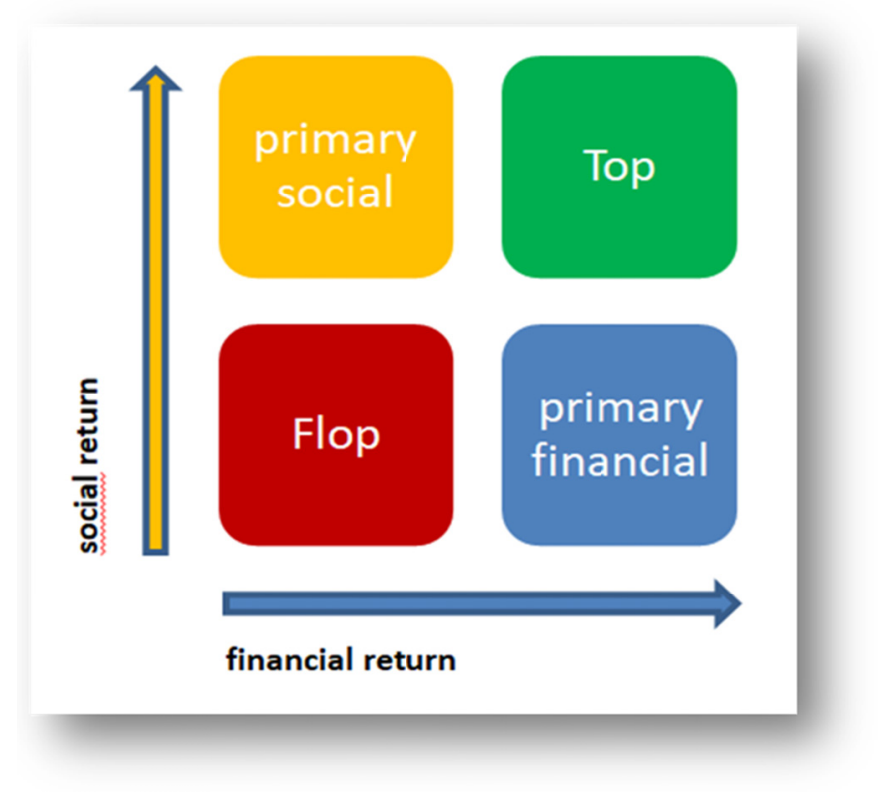

Figure 3. Return Matrix

The Return Matrix looks useful. There is no information about the theory behind this model or about the formulas, for example the factors or the KPIs, in literature. It is used by two of the largest Dutch housing corporations. So, two interviews were planned, one for each corporation: Havensteder (with Floris Ledder) and Vestia (with Paul Tazelaar). The interviews with members of the policy staff of these corporations was designed to collect additional information about the model itself, and to discuss the norms, the key performance indicators and the needed information and data.

These interviews showed that the existing model is mainly about how to think. The Return Matrix was not worked out in factors, KPIs, norms, scales etc. Floris Ledder advised to use the tactical KPIs for this model.

\subsection{Criteria for a Model}

The outcome of the interviews with the stakeholders was the assignment to make a clear strategy, communicate it clearly and stick to it for long. Values which were considered important for the property were technical quality, energy quality, diversity and affordability. In addition, a preference for smaller houses and attention for lonely or disordered people showed up. Besides, the local counsel offered help. The DESTEP analysis consists of a demographic, economic, social, technological, ecological and a political analysis, resulting in a SWOT. The quality of the service, rentability, financial position and the collaboration with stakeholders are considered strong points. The old houses, technical quality, energy quality, affordability, slow decision making and quality of life are weak factors. Opportunities are the strong market demand, collaboration and the use of new energy solutions. Risks are disappearing subsidies, decreasing cash flows through additional taxes, financeability and rentability.

Table 2. score table

\begin{tabular}{cc}
\hline Score & Valuation \\
\hline 1 & Very bad \\
2 & Bad \\
3 & Sufficient \\
4 & Good \\
5 & Very good \\
\hline
\end{tabular}


Table 3. Criteria for model

\begin{tabular}{cccc}
\hline Criteria & Aedex model & Subjective model & Integrated model \\
\hline Clarity & 2 & 4 & 5 \\
Reliability & 4 & 2 & 4 \\
Measurability & 5 & 2 & 4 \\
Rapidity & 2 & 5 & 5 \\
Price & 3 & 5 & 5 \\
\hline
\end{tabular}

The interviews with stakeholders gave insight into the most important standards a good strategy should meet according to them. The first thing they asked for was clarity and honoring existing commitments. This made clear there was only one chance to make a good plan. Their second priority was the environment and energy, followed by technical quality and diversity of stock. The last prime factor was affordability. An interesting aside for the housing corporation was the suggestion that the houses could be smaller. So, the most important criteria for the model are clarity or unambiguity, reliability, measurability, rapidity and price. The most important factors are technical quality, energy quality, finance, old houses, affordability and the quality of life.

\subsection{Choice of Model}

The BCG matrix is a well-known instrument for strategic decision making. The upsides of the BCG matrix are the price, rapidity and reliability. The downside for social housing corporations is that it does not facilitate the process of decision making, while it does not measure the right things either, so it does not provide much clarity and not much unambiguity. The interviews with experts showed that the Return Matrix can provide much clarity, reliability, measurability, rapidity and a low price. These interviews were a great inspiration to me, because they showed that this instrument meets all the criteria we should meet.

\begin{tabular}{|c|c|c|c|c|c|c|}
\hline $\begin{array}{l}\text { Morphological map: } \\
\text { Alternate solutions }\end{array}$ & & 1 & 2 & 3 & 4 & 5 \\
\hline Clarity & Aedex & & & & & \\
\hline Reliability & 1"10й & & & & & \\
\hline Measurability & model & & & & & \\
\hline Rapidity & Integrated & & & & & \\
\hline Price & model & & & & & \\
\hline
\end{tabular}

Figure 4. Morphological map for the alternate solutions

\subsection{Choice of Factors}

The model uses two dimensions: financial return and social return.

\subsubsection{Financial Return Dimension}

To realize a new strategy, a housing corporation has to borrow money. The most important organization regarding loans for this sector in the Netherlands is the WSW. They provide banks with financial guarantee. The WSW uses an instrument to measure the financial situation of each housing corporation.

In practice, two KPIs are most important. ICR (Interest Coverage Ratio) is most important for the short term and $\mathrm{LtV}$ (Loan to Value) is most important for the long term. ICR and LtV are widely accepted and used, and very useful. The norms of the WSW limit the financial possibilities of a Dutch housing corporation. The norm of the WSW for the long term is LtV. The case study establishes the LtV of the WSW to be the most important financial KPI for making strategic asset management policy.

The loan and the value can be influenced by strategy. The loan is the outcome of the policy. This makes the value 
the part to be actively influenced. So, a good method to measure the success of the strategic asset management policy should measure the value. According to the policy of WSW, the value is defined as the NPV (Net Present Value, in Dutch the 'Bedrijfswaarde'). This dimension is composed of income (rent) and expenses (maintenance, management and interest costs). The NPV is widely accepted, used and useful too. So, the value is the factor and the NPV is the KPI.

Table 4. Financial Return KPI's

\begin{tabular}{|c|c|c|c|c|c|}
\hline \multirow[b]{2}{*}{$*$} & Instruments & \multirow{2}{*}{$\begin{array}{l}\text { Values } \\
\text { weight }\end{array}$} & \multirow[b]{2}{*}{ value 0} & \multirow[b]{2}{*}{ value 6} & \multirow[b]{2}{*}{ value 10} \\
\hline & $K P I ' s$ & & & & \\
\hline & Financial value & $100 \%$ & & & \\
\hline$*$ & NPV (Net Present Value) in $€$ & $100 \%$ & - & 30.000 & 50.000 \\
\hline
\end{tabular}

Table 5. Social Return KPI's

\begin{tabular}{|c|c|c|c|c|c|}
\hline \multirow[b]{2}{*}{$*$} & Instruments & Values & & & \\
\hline & $K P I ' s$ & weight & value 0 & value 6 & value 10 \\
\hline & Energetic quality & $20 \%$ & & & \\
\hline \multirow[t]{2}{*}{$*$} & Energy index & $20 \%$ & 2,50 & 2 & 1,00 \\
\hline & Affordability & $20 \%$ & & & \\
\hline$*$ & Net rent in $€$ & $10 \%$ & 710 & 524 & 400 \\
\hline \multirow[t]{2}{*}{$*$} & rent class & $10 \%$ & 5 & & 1 \\
\hline & Living pleasure & $20 \%$ & & & \\
\hline$*$ & WWS points & $5 \%$ & 80 & 134 & 170 \\
\hline * & accessibility & $5 \%$ & 0 & 6 & 10 \\
\hline$*$ & WOZ (registered) value in $€$ & $5 \%$ & 70.000 & 178.000 & 250.000 \\
\hline \multirow[t]{2}{*}{$*$} & M2 & $5 \%$ & 40 & 58 & 70 \\
\hline & Real Estate Quality & $20 \%$ & & & \\
\hline$*$ & Condition 'score' & $3 \%$ & 1 & 6 & 10 \\
\hline$*$ & condition ROG (Red-Orange-Green) & $3 \%$ & 0 & & 10 \\
\hline$*$ & Lifespan in years & $3 \%$ & 0 & 20 & 33 \\
\hline * & Age in years & $3 \%$ & 75 & 30 & 0 \\
\hline$*$ & complaints maintenance ( $€ /$ vhe $)$ & $2 \%$ & 1.000 & 400 & 0 \\
\hline$*$ & complaints per house & $2 \%$ & 3 & 1 & 0 \\
\hline * & mutation maintenance & $2 \%$ & 1.000 & 400 & 0 \\
\hline \multirow[t]{2}{*}{$*$} & technical ROG (Red-Orange-Green) & $2 \%$ & red & orange & green \\
\hline & Livability & $10 \%$ & & & \\
\hline$*$ & $\mathrm{WOZ} / \mathrm{M} 2$ & $5 \%$ & 1.500 & & 2.000 \\
\hline \multirow[t]{2}{*}{$*$} & Livable ROG (Red-Orange-Green) & $5 \%$ & 0 & 2,4 & 4 \\
\hline & Rentability & $10 \%$ & & & \\
\hline * & reaction rate & $3 \%$ & 0 & & 100 \\
\hline * & refusals & $3 \%$ & 10 & & 0 \\
\hline$*$ & Rentable ROG (Red-Orange-Green) & $4 \%$ & red & orange & green \\
\hline
\end{tabular}




\subsubsection{Social Return Dimension}

Loosbroek (2005) describes the factors and KPIs needed to measure the success of tactical plans and realization. These factors are primarily affordability, availability and technical quality. Next are popularity and the quality of living and life. The new factor is sustainability, added due to current events. Because of missing information about which factor is more important, all these factors were selected and used with the same weight in our model. After consulting the management team, the Social Return Dimension was composed of energy quality (20\%), affordability $(20 \%)$, residential quality $(20 \%)$, technical quality $(20 \%)$, quality of life $(10 \%)$ and rentability $(10 \%)$.

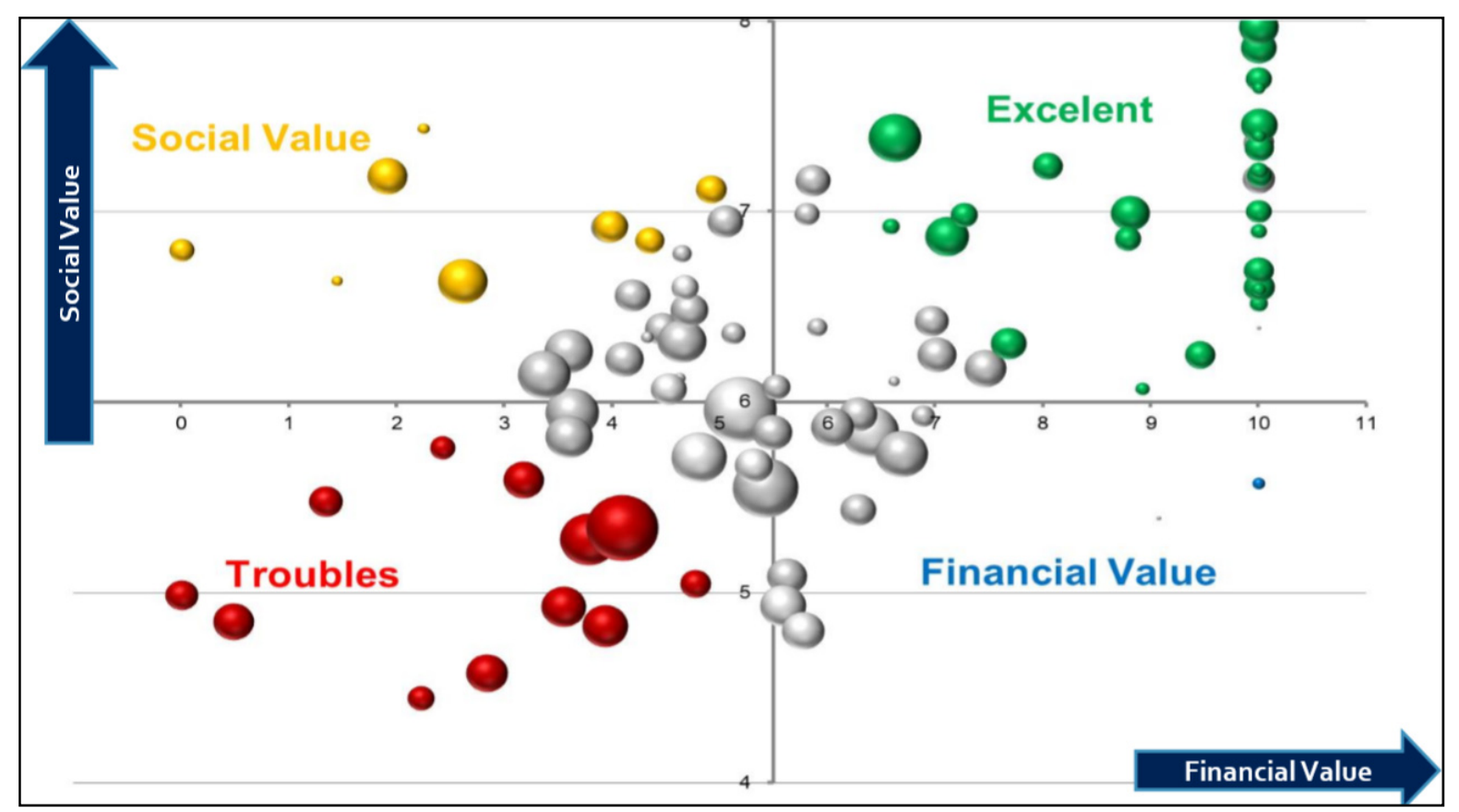

Figure 5. Final result of the research (optimized for the colors)

\subsection{Choice of KPIs}

Conijn (2017) presents a Dutch study about the use of tactical KPIs. This was helpful. Because of missing information about which KPI is more or most important, all these KPIs were selected and used with the same weight. For this case, 23 KPIs were used.

\subsection{Addition of Data}

All necessary data was available. So, a data model was made, the data were added and the 'Return Matrix' (in Dutch 'Rendementsmatrix') was composed. The next step was checking and validating the outcome on both axes with experiential experts from Finance and ICT. Except for a few small details, no adjustments were needed.

\subsection{Increase of Reliability}

To identify the unidentified information, we interviewed professionals from the housing corporation. To classify the unclassified information, we used the 'traffic light method'. By combining these two methods, the color red, orange or green was assigned to every group of houses for its technical quality, its quality of life and its rentability. Up-to-date financial information was used for determining the financial return of each group of houses. Using the Likert-scale, this information was transformed into a rating for each group of houses.

The outcome visualized that there is a 'top 10' of groups of houses which need more attention because of the low financial and strategic scores (dark red+ on the chart). In addition to the scoring and ranking sessions, the arguments for the rankings were discussed. These discussions showed that the professionals know a lot about the property and if the right question is asked, they provide essential information. The answers were very helpful in finding out how to realize a lot of quality improvement with little money.

Comparing the chart 'Final result of the research' (figure 9) with the 'Chart on base of the internal interviews' (figure 11), it can be concluded that the same objects appear in the top 10 results (= red) of both charts. This fact was very helpful in creating support for the implementation stage, because that the message internal professionals picked up, was: "You already knew it. The only thing the management had to do, was to ask the 
right questions."

\begin{tabular}{|r|l|c|l|l|l|l|}
\hline cplx.nr & name & Group & tech. & rent. & liv. & fin. \\
\hline 40 & $(040)$ Pleiadenplantsoen $Z$ & 5 & orange & green & green & orange \\
\hline 41 & $(041)$ Schutterstraat & 4 & green & green & green & orange \\
\hline 42 & $(042)$ Bellatrixstraat & 2 & green & green & red+ & orange \\
\hline 43 & $(043)$ Eridanusstraat & 6 & green & green & green & green \\
\hline 44 & $(044)$ Willebrordstraat & 2 & red + & red & orange & orange \\
\hline 45 & $(045)$ Hazevlak & 1 & red + & red & orange & red+ \\
\hline 46 & $(046)$ Gildenlaan & 2 & green & red+ & red+ & orange \\
\hline
\end{tabular}

Figure 6. Output of 'traffic-light-method'

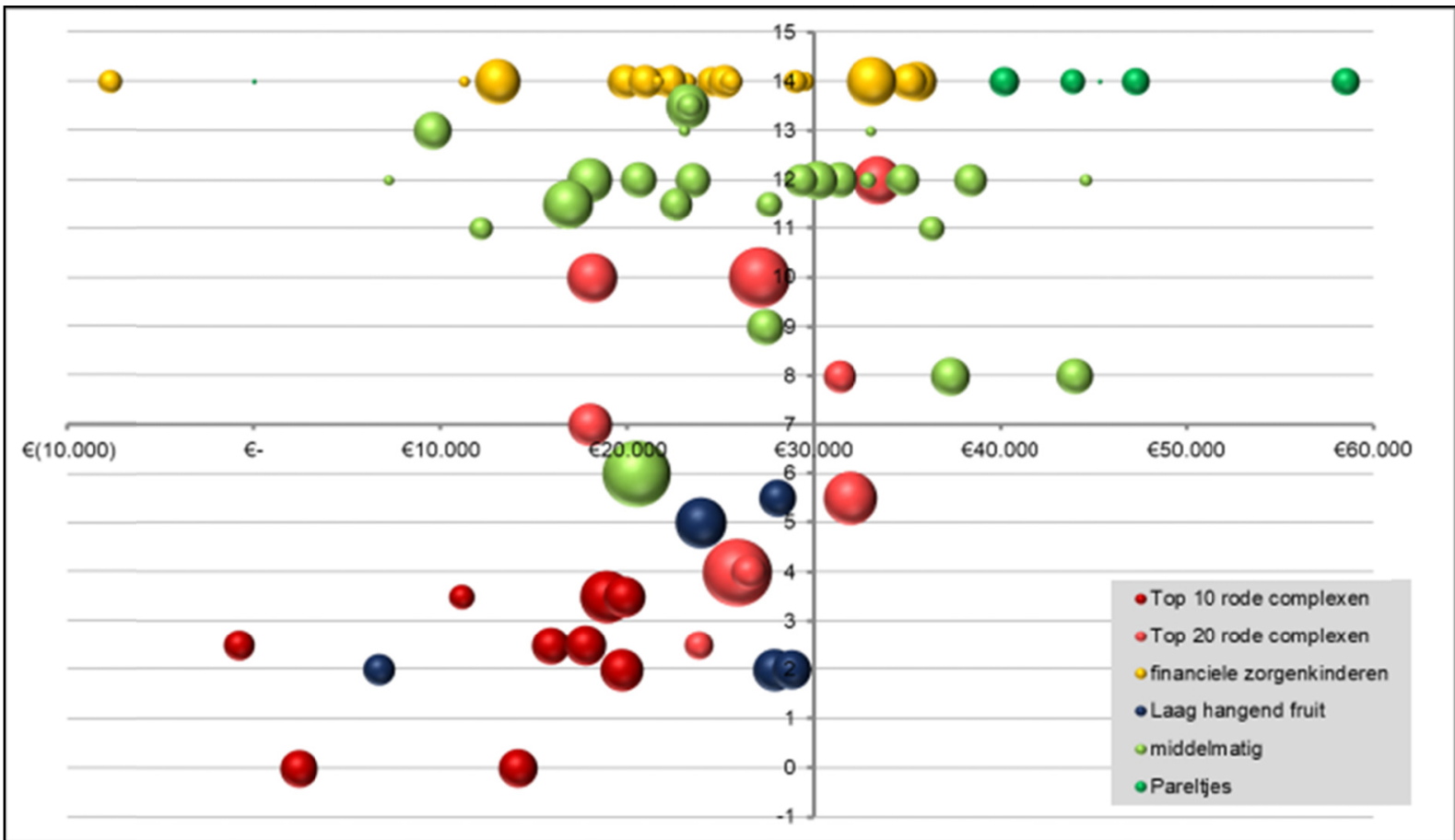

Figure 7. Result of the 'traffic-light-method' (not optimized for the colors)

\section{Discussion}

The case study was carried out according to the DESTEP analysis. This analysis determined objective criteria for measuring the success of the strategy: technical, energy and living quality of the houses, value for money, and financial strength of the corporation. Local presence and visibility of local involvement of the corporation are also important. The case study of the property information shows the houses are old, the quality is low, the sustainability is low and the rent is low. So, there is a serious gap between these results and the criteria of the DESTEP analysis.

The financial case study was about the possibilities to invest in the realization of a strategic plan. First of all, there is a free monthly cash income of 1 million euros. So, for the next five years there will be 60 million euros available for investment. To invest more money, the housing corporation has to rent money. To increase the loan, WSW backing is necessary, and the most important KPI for this housing corporation is the LtV. This makes the LtV one of the borders of a new strategic plan. LtV has two parts: loan and value. Loan is the output of the plan. Value can be influenced by strategy. The Financial Value of the Real Estate for a housing corporation is the NPV (Net Present Value, 'Bedrijfswaarde' in Dutch). The second outcome of the financial case study is that the loan 
can increase with a maximum of 100 million euros. This totals 160 million euros as the maximum for investment. This is not enough to do what is needed for all the houses. The situation is urgent too, because of the expected, rapidly emerging technical and financial changes as well as changing public policies. So, the corporation has to make a plan and they need an instrument to measure the quality of the plan. The Return Matrix does it all.

\subsection{Discussion of the Norms for Resilient Strategic Asset Management Policy}

A good strategic management policy is well-balanced between what is needed and what is possible. Besides, a good strategy should allow for its quality to be measured. A resilient strategy should have the option of being monitored, preferably each year and at least once in five years. It is also important the strategy can be translated to the tactical level. And, last but not least, to increase reliability, it is important to integrate as much information as available. The Return Matrix does it all.

\subsection{Discussion of Conditions for An Improved Method}

The need for this model is found in asset management, which fits the model of the "Beleids8baan" as described in Os (2013). And the opportunity necessary is found in financial policy, which fits one of the norms of the WSW. The translation into practical terms is new and not found in existing literature. The possibility to compare the known to the unknown data (to the data with the opinions) is new and makes it possible to get additional information and increase reliability.

With the Return Matrix as an integrated tool, it is possible to fix the strategic problem of decision making. It integrates technical data, environmental data, financial data and the expert opinions of the professionals involved. The integrated approach to a closed asset management strategy and policy (between strategy and tactics) has now become available. This model for creating strategy and policy will make it possible to decide about adjustments to the strategy based on facts gained from measuring the results of former adjustments to the strategy.

\subsection{Discussion of the Decision-Making Result}

The internal application of this model was meant to facilitate decision making regarding strategy (five years) and vision (twenty years) for the management team. It generated a lot of support from and understanding among the experts, the staff and the other colleagues.

The external application of this model resulted in agreement from and cooperation with the municipal executive, support and understanding from the civil servants and acceptance from the tenants.

The (very satisfied) CEO found this model very helpful because of the unambiguous visual representation, the combination of the different sources of information and the widely supported outcome, internally ánd externally. They have not changed anything after the model was finished.

\subsection{Conclusions and Recommendations}

Taking everything discussed above into consideration, it will not be difficult to compose the instrument for other cases too. The clarity of the instrument gives direction to and understanding of the necessary decisions. This was very helpful while gaining support from the many stakeholders, such as the board, the management team, the professionals and the policy staff of the housing company; but also from the local tenants, civil servants and the municipal executive. This support was very helpful in the process of planning and taking a final decision. It also helped decrease the time and effort this process took. The factors and the KPIs of the instrument were helpful in clarifying the reasons behind the decisions.

Another conclusion is that strategic questions can be answered by asking the right people the right questions in the right way without using specific data, because the internal professionals have the information in their minds. This information can be used by an instrument as a quick scan and as a check to increase its reliability.

It is recommended:

1. To be aware of any low-hanging fruit, because this is valuable and good value for money.

2. Also, it is important to document the steps taken while composing the instrument for any specific case and to remember what information was necessary for this process. Now all this information and knowledge is available, but this might not be so at the time an update of the instrument will be necessary in five years' time. To prevent wasting time in the future, make sure to store this information carefully!

3. Making a new policy is time consuming, so it is recommended to start making the update a year before finishing the actual policy. Objective information is valuable for performance improvement, so participating and using a benchmark is recommended. 
4. Finally, a house is much more than just KPIs, so go out and have a look to check the plan with reality to prevent making an expensive, wrong decision.

WSW is planning to change the content of 'value' in the near future. This can influence the outcome of the instrument. It is WSW's expectation there will only be a small effect.

It was a surprise this elementary instrument (and its detailed elaboration) had not been available in scientific literature before: this provided a good reason to write this Journal Paper. It would be interesting to further investigate any possibilities to improve the 'Return Matrix' by reducing the amount of KPIs of the instrument, maybe to 5 or 6 KPIs.

\section{References}

Aalbers, Manuel B. (2017). The Financialization of a Social Housing Provider. International Journal of Urban Regional Research, 41(4), 572-587, conference paper, https://doi.org/10.1111/1468-2427.12520

Boerenfijn P. (2018). A multi-case study of innovations in energy performance of social housing for older adults in the Netherlands. Energy and Buildings, 158(1), January 2018, Pages 1762-1769. https://doi.org/10.1016/j.enbuild.2017.10.101

Buitelaar, Edwin \& Arjan Bregman. (2016). Dutch land development institutions in the face of crisis: trembling pillars in the planners' paradise. European Planning Studies, 24, Theme issue: Crisis and renewal of contemporary urban planning, Pages 1281-1294. https://doi.org/10.1080/09654313.2016.1168785

Conijn, Johan. (2013). Portefeuille sturing bij Woningcorporaties. Rotterdam: Ortec-Finance

Conijn, Johan. (2017). Handreiking performance analyse. http://insights.ortec-finance.com/nl-nl/ 2017/10/16/handreiking-performance-analyse, 19-03-2018.

Gruis, Vincent. (2005). Financial and Social Returns in Housing Asset Management: Theory and Dutch Housing Associations' Practice. Urban Studies, 42(10), 1771-1794, September 2005. https://doi.org/10.1080\%2F00420980500231696

Hollow, Matthew. (2010). Governmentality on the Park Hill estate: The rationality of public housing. Urban History, 37(1), 117 - 135. 1 april 2010. https://doi.org/10.1017/S096392681000009X

Loon, Jannes van. (2017). How real estate became 'just another asset class. European Planning Studies, 25(2), Pages 221-240. https://doi.org/10.1080/09654313.2016.1277693

Loosbroek. (2005). Strategische Voorraadbeleid van Woningcorporaties, http://docplayer.nl/12752427-Strategisch-voorraadbeleid-van-woningcorporaties.html , 19-03-2018.

Mossel, Henk-Jan van \& Sylvia J.T. Jansen. (2010). Maintenance services in social housing: what do residents find important? Structural Survey, 28(3), 215-229. https://doi.org/10.1108/02630801011058942

Nieboer, Nico. (2005). How strategic is housing asset management of institutional real estate investors? Property Management, 23(1), 22-32. https://doi.org/10.1108/02637470510580561

Nieboer, Nico \& Vincent Gruis. (2016). The continued retreat of non-profit housing providers in the Netherlands. Journal of Housing and the Built Environment, 31(2), 277-295. https://doi.org/10.1007/s10901-015-9458-1

Os, P. Van (2013). Mensen, stenen, geld - Het beleidsproces bij woningcorporaties. Rigo Research \& Advies BV.

Tajani, Francesco \& Pierluigi Morano. (2015). An evaluation model of the financial feasibility of social housing in urban redevelopment. Property Management, 33(2), 133-151. https://doi.org/10.1108/PM-02-2014-0007

Tu, Qi. (2017). House prices and long-term equilibrium in the regulated market of the Netherlands. Housing Studies, 1-25, Received 09 Jul 2015, Accepted 21 Jun 2017, Published online: 18 Jul 2017. https://doi.org/10.1080/02673037.2017.1346786

Veenhoven, Ruut (2002). Why social policy needs subjective indicators. Social Indicators Research, 58, 33-45, ISSN 0303-8300. https://doi.org/10.1023/A:1015723614574

\section{Copyrights}

Copyright for this article is retained by the author(s), with first publication rights granted to the journal.

This is an open-access article distributed under the terms and conditions of the Creative Commons Attribution license (http://creativecommons.org/licenses/by/3.0/). 